\title{
Estudo da atividade hipoglicemiante e antibacteriana de polissacarídeos obtidos a partir da levedura Candida zeylanoides
}

\author{
Gláucia Lais Pereira Lima Neco ${ }^{1}$; Sandra Aparecida de Assis ${ }^{2}$; Anny Carolinny \\ Tigre Chaves ${ }^{3}$ \\ 1. Bolsista PIBIC/CNPq, Graduando em Farmácia, Universidade Estadual de Feira de Santana, e-mail \\ glaucialaisneco@hotmail.com \\ 2. Orientador, Departamento de Saúde, Universidade Estadual de Feira de Santana, e-mail: \\ sandrinhaassis@yahoo.com,br \\ 3. Participante do projeto, Departamento de Saúde, Universidade Estadual de Feira de Santana, e-mail: \\ annytigre@hotmail.com
}

PALAVRAS-CHAVE: Polissacarídeo; Leveduras; Semi-árido.

\section{INTRODUÇÃO}

O isolamento de micro-organismos de ambientes onde se conhece pouco da biodiversidade microbiana, como o semi-árido nordestino, tem incentivado, nas últimas décadas, um aumento nos estudos de bioprospecção microbiana. Desta forma, pesquisas envolvendo o potencial biotecnológico desses organismos vem proporcionando a descoberta de novos produtores de compostos bioativos de alto valor agregado (LIU et al., 2012; SMRITHI et al., 2013; MONCIARDINI et al., 2014).

Atualmente, a pesquisa de compostos bioativos naturais com aplicação no tratamento e prevenção de doenças humanas tem vindo a ganhar cada vez mais importância (DONADIO et al., 2010).

Os fungos são conhecidos por seu papel ambiental, por sua versatilidade na obtenção de metabólitos secundários e pela facilidade na reprodutibilidade de resultados, porém, apesar dos fungos serem reconhecidos como uma importante fonte de produtos bioativos naturais é estimada que, uma grande quantidade destes compostos, se encontre ainda por identificar (SANTOS, 2012; HIGGINBOTHAM, 2013).

\section{MATERIAL E MÉTODOS OU METODOLOGIA}

O micro-organismo do estudo foi a levedura Candida zeylanoides, código CCMB 244 pertencente a coleção de cultura de micro-organimos da Bahia (CCMB, Feira de Santana, Brasil).

\section{Producão e Extracão de Polissacarídeos}

O micro-organismo foi inoculado em placa de Petri contendo meio YM sólido (extrato de levedura 3,0 g/L; extrato de malte 3,0 g/L; peptona de carne 5,0 g/L; glicose $10,0 \mathrm{~g} / \mathrm{L}$ e ágar $15,0 \mathrm{~g} / \mathrm{L}$ ) e cultivados em estufa de crescimento a $28^{\circ} \mathrm{C}$. Após esse período de crescimento, alçadas do micro-organismo foram inoculados em solução salina $0,45 \%$ até alcançar a absorbância de aproximadamente $1 \mathrm{~nm}, 10 \mathrm{ml}$ deste inóculo foram acrescentados em $100 \mathrm{ml}$ de meio YM liquido (extrato de levedura 3,0 g. $\mathrm{L}^{-1}$, extrato de malte 3 g.L $\mathrm{L}^{-1}$, peptona 5 g.L $\mathrm{L}^{-1}$, glicose 10 g.L $\mathrm{L}^{-1}$ ). A fermentação ocorreu em shaker rotatório sob condições de $28^{\circ} \mathrm{c}$ a $100 \mathrm{rpm}$, por cinco dias. Após o período fermentativo, o material foi centrifugado a 10.000 rpm por 10 minutos para a extração da biomassa. O exopolissacarídeo (EXO) foi obtido partir do sobrenadante com etanol absoluto na proporção de 3:1 (etanol/sobrenadante), a $4^{\circ} \mathrm{C}$ por 24 horas.

\section{Otimizacão da Amostra obtida}


A metodologia avaliou o comportamento da biomassa e o exopolissacarídeo em relação ao tempo e temperatura em solução de $\mathrm{NaOH}$ a $1 \mathrm{M}$, onde $0,300 \mathrm{~g}$ do material seco a ser purificado (exopolissacarídeo e biomassa) e $3 \mathrm{~mL}$ de solução de $\mathrm{NaOH}$ (proporção 1:10), foram incubados em banho-maria em temperaturas de $50^{\circ} \mathrm{C}, 70^{\circ} \mathrm{C}$, $90^{\circ} \mathrm{C}$ no intervalo de tempo que variavam de 60 a 180 minuto.

\section{Determinacão da atividade hipoglicemiante in vitro}

A metodologia da atividade inibitória da enzima $\alpha$-amilase foi adaptada do método de Caraway. Assim, a solução enzimática foi homogeneizada com a amostra e solução tampão e colocada em banho-maria a $37^{\circ} \mathrm{C}$ por 15 minutos. Em seguida, foi adicionado o substrato que estava no banho-maria a $37^{\circ} \mathrm{C}$ por 2 minutos e, por fim, foi adicionado o reagente de cor e a água, sendo que esta solução foi colocada em banhomaria por 7 minutos e 30 segundos. Tal procedimento foi realizado com os controles negativo e positivo e padrão, diferenciando apenas na ausência da enzima no padrão. A leitura foi feita no espectrofotômetro em $660 \mathrm{~nm}$.

\section{Determinacão da atividade antibacteriana}

A Concentração Inibitória Mínima (CIM) dos polissacarídeos fúngicos frente às bactérias S. aureus ATCC 29213, K. pneumoniae ATCC 25922, P. aeruginosa ATCC 27853, E. coli ATCC 25922 e P. mirabilis ATCC 17407 foram determinados pelo método de microdiluição em caldo (CLSI, 2006). Após expansão das bactérias em caldo nutriente por $24 \mathrm{~h}$ a $37^{\circ} \mathrm{C}$, estas foram diluídas em caldo nutriente para $10^{5} \mathrm{UFC} / \mathrm{mL}$ e incubadas com as amostras $(10,6,3,1 \mathrm{mg} / \mathrm{mL})$ por $24 \mathrm{~h}$ a $37^{\circ} \mathrm{C}$. Após esse período, resazurina $(0,01 \%)$ foi adicionada à suspensão e o CIM foi determinado como sendo a menor concentração onde não houve crescimento bacteriano após $1 \mathrm{~h}$, indicado pela coloração azul.

\section{RESULTADOS E/OU DISCUSSÃO}

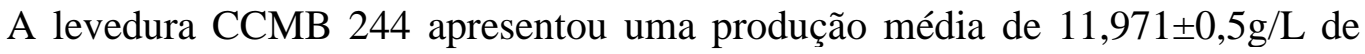

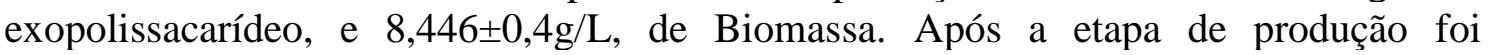
otimizado os produtos e definidos as condições idéias e o ponto ótimo de produtividade. Os resultados gráficos do experimento foram avaliados através do Statistic, onde mostraram o comportamento da fração solúvel da biomassa e do exopolissacarídeo purificado em relação às variáveis do estudo.

O gráfico de superfície de resposta e curva de níveis mostrou em relação ao ponto ótimo do experimento para Biomassa solúvel, temperatura de $62,3^{\circ} \mathrm{c}$ no tempo de 153 minutos. Os modelos propostos foram validados pela análise de variância ANOVA, com regressão correspondente $\mathrm{F}=60,49$ e em relação ao ajuste o $\mathrm{F}$ calculado=5,3, os dados referentes o coeficiente de correlação $\mathrm{R}^{2}=0,99$ mostraram que $99 \%$ dos dados podem ser explicados pelo modelo proposto.

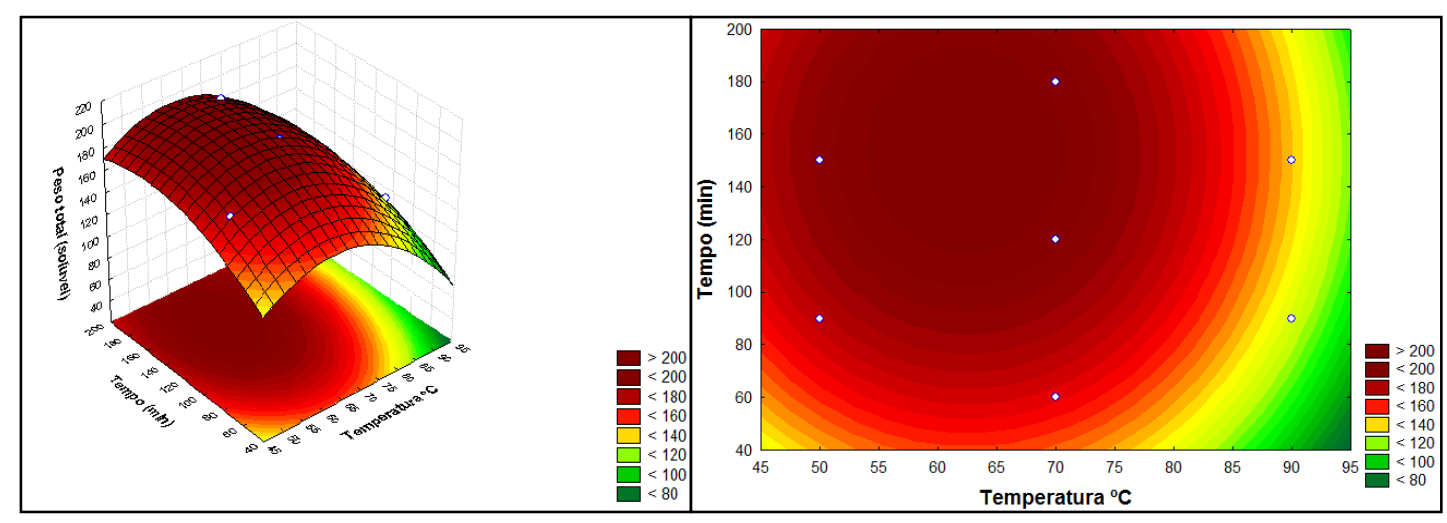


Figura 01: Gráfico superfície de resposta e curva de níveis - Influência do tempo e da temperatura na otimização da fração solúvel da Biomassa do micro-organismo CCMB 244

Para o EXO o ponto ótimo foi cálculo em $66^{\circ} \mathrm{C}$ em 121 minutos para a fração solúvel do EXO 244 de acordo como o programa Statistic. De acordo com a análise de variância ANOVA, o coeficiente de correlação $\mathrm{R}^{2}=0,95$, ou seja, $95 \%$ dos dados podem ser explicados pelo modelo proposto. A regressão $\mathrm{F}=13,67$ e o ajuste $\mathrm{F}=10,28$.

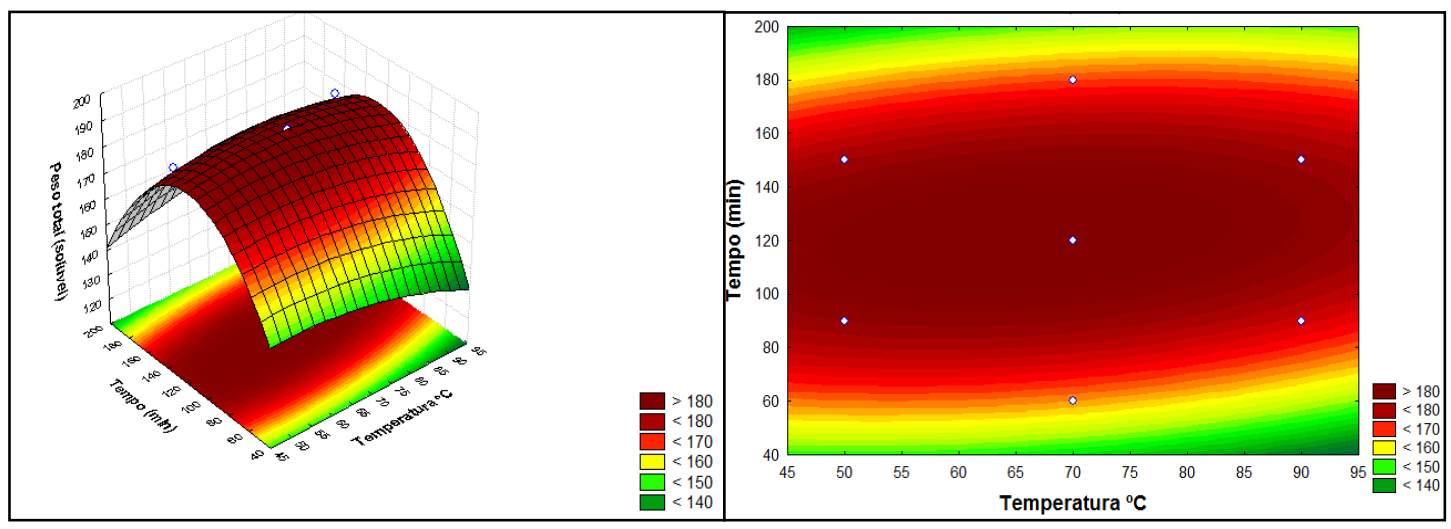

Figura 02: Gráfico superfície de resposta e curva de níveis - Influência do tempo e da temperatura na otimização da fração solúvel do exopolissacarídeo CCMB 244

Analise da atividade biológica justifica-se, pela prevalência da diabetes que tem vindo aumentando nos últimos tempos, ocupando um maior espaço no perfil de morbilidade e mortalidade da população mundial (Sargis, 2014). E pelo uso da arcabose como hipoglicemiante oral conhecido, sendo este um pseudotetrassacarídeo.

A atividade frente à enzima $\alpha$-amilase testada com o polissacarídeo CCMB 244 em solução de concentração $10 \mathrm{mg} / \mathrm{mL}$, apresentou inibição de $67,3 \%$. Devido a atividade inibitória enzimática apresentada, foi possível calcular o IC50, dentro das concentrações de 5,3 e $1 \mathrm{mg} / \mathrm{mL}$.

Tabela 09: Inibição da enzima amilase por polissacarídeo do micro-organismo CCMB 244

\begin{tabular}{|c|c|c|}
\hline Amostra & Inibição enzimática (\%) & IC50 (mg/mL) \\
\hline CCMB 244 & $67,3 \%$ & $3,615 \pm 0,07^{*}$ \\
\hline Acarbose & - & $0,019 \pm 0,00$ \\
\hline
\end{tabular}

Além da atividade hipoglicemiante, o polissacarídeo da levedura Candida zeylanoide, teve seu potencial antibacteriano avaliado. No entanto, não apresentou qualquer atividade frente às bactérias testadas na concentração de até $10 \mathrm{mg} / \mathrm{mL}$.

\section{CONSIDERAÇÕES FINAIS (ou Conclusão)}

O estudo com o micro-organismo CCMB 244, Candida zeylanoides, mostrou ser promissor, o método de produção, extração e otimização mostraram satisfatórios de acordo com as metodologias propostas. Os polímeros extraídos apresentaram características para serem explorados em atividade biológicas tanto em in vitro como in vivo. Ademais, esse estudo evidenciou a atividade inibitória enzimática frente à $\alpha$ amilase sendo uma peça útil para o tratamento da diabetes.

\section{REFERÊNCIAS}


CLSI. 2006. Methods for Dilution Antimicrobial Susceptibility Tests for Bacteria That Grow Aerobically; Approved Standard-Ninth Edition. CLSI document M07-A7. Wayne, PA: Clinical and Laboratory Standards Institute.

DONADIO, S. et al. 2010. Antibiotic discovery in the twenty-first century: current trends and future perspectives. The Journal of antibiotics, v.63, n.8, p.423-430.

HIGGINBOTHAM, S. J. et al. 2013. Bioactivity of fungal endophytes as a function of endophytes taxonomy and the taxonomy and distribuition of their host plants. PloS

One, v.8, n.9, p. 73192.

LIU, X. et al. 2012. Systematics-guided bioprospecting for bioactive microbial natural products. Antonie van Leeuwenhoek, v. 101, n. 1, p. 55-66.

MONCIARDINI, P. et al. 2014. Discovering new bioactive molecules from microbial sources. Microbial biotechnology, v. 7, n. 3, p. 209-220.

SANTOS, S. N. 2012. Bioprospecção de biomoléculas isoladas de fungos endofíticos de Cobretum leprosum do bioma Caatinga. Escola Superior de Agricultura Luiz de Queiroz, Tese.

SMRITHI, S. et al. 2013. Bioprospecting of Microbes Producing Commercially Useful Products. PHARMANEST - An International Journal of Advances in Pharmaceutical Sciences, v. 4, n. 6, p. 1419-1426. 